\title{
Escherichia coli bacteriuria in pregnant women in Ghana: antibiotic resistance patterns and virulence factors
}

\author{
Akua Obeng Forson*, Wilson Bright Tsidi, David Nana-Adjei, Marjorie Ntiwaa Quarchie \\ and Noah Obeng-Nkrumah
}

\begin{abstract}
Objectives: The relevance of Escherichia coli associated bacteriuria infection in pregnant women is poorly understood, despite these strains sharing a similar virulence profile with other pathogenic E. coli causing severe obstetric and neonatal infections. We characterized and determined the antimicrobial susceptibility, resistance genes and virulence profiles of $82 \mathrm{E}$. coli isolates associated with asymptomatic bacteriuria in some pregnant in Ghana from February to August 2016 using Kirby-Bauer disc diffusion and polymerase chain reaction.

Results: High levels of antimicrobial resistance were observed to ampicillin (79.3\%), tetracycline (70.7\%) and cotrimoxazole (59.8\%), except for cefuroxime (32.9\%). Resistance genes analyses revealed $58.5 \%$ were positive for $B / a_{\text {TEM }}$ and 7.3\% for aph(3)-la(aphA2). Virulence factors (VFs) was more widespread in pregnant women in the 2 nd and $3 r d$ trimesters than 1st trimester. VFs relating to adhesion (papC and iha), Protectins (traT), aerobactin acquisition (iutA) and iron acquisition systems (fyuA and irp2) were more prevalent in the resistant E. coli isolates. This study provides evidence for a link in bacteriuria and transmission of extra-intestinal E. coli in pregnant women to cause multi-resistant obstetric or neonatal infections. Considering the involvement of extra-intestinal E. coli in infections, results are helpful to develop strategies to prevent maternal and/ neonatal infections.
\end{abstract}

Keywords: Escherichia coli, Bacteriuria, Pregnant women, Ghana

\section{Introduction}

In pregnant women, the odds of acquiring urinary tract infections (UTI) from untreated bacteriuria is high, with consequent risk for preterm labour [1]. Pregnant woman diagnosed with bacteriuria are thus offered antibiotics to prevent complications $[2,3]$. The extraintestinal pathogenic E. coli (ExPEC) are a major cause of UTI in pregnancy [4-6]. The ExPEC harbour diverse but specific virulence factors (VFs) with the potential to colonize highly specialized ecological niches, such as the urogenital tract [7-11]. Furthermore, multidrug-resistance traits in many ExPEC strains involved in bacteriuria is increasing accounting for considerable amount of morbidity, and

*Correspondence: obeng.akua@yahoo.com; asobeng@ug.edu.gh Department of Medical Laboratory Science, School of Biomedical and Allied Health Sciences, College of Health Sciences, University of Ghana, Legon, Accra, Ghana can lead to significant mortality in pregnant women with UTI [12-15]. There is however paucity of data in subSahara Africa where such infections are likely to be common and devastating due to high exposure to infectious organisms and limited access to health care services [1, 13-20]. In Ghana, the aetiology of E. coli in bacteriuria are well documented [21-25] but often limited to phenotypic tests with little knowledge on virulence factors. This study aimed to characterize ExPEC strains, and determine their virulence and antimicrobial resistance potential in urine samples of pregnant women.

\section{Main text}

Materials and methods

Sample collection and processing

The approximated sample size of 400 was calculated using the formula $\mathrm{N}=\mathrm{Z}^{2} \mathrm{P}(1-\mathrm{P}) / \mathrm{D}^{2}$ where; $\mathrm{N}=$ sample size; $Z=95 \%$ (1.96) confidence interval; $P=$ previous 
reported prevalence of UTI among pregnant women in Ghana (56.5\%) [26], and $\mathrm{D}=$ allowable margin error of 0.05 . The 400 pregnant women were recruited into this study after the provision of informed consent. Pregnant women on antibiotics were excluded. A self-administered questionnaire was used to obtain information on demographic and socio-economic characteristics (Additional file 1: S1 file). Mid-stream-clean-catch urine from participants were inoculated onto cysteine lactose electrolyte deficient (CLED) agar and incubated at $37{ }^{\circ} \mathrm{C}$ for $24 \mathrm{~h}$ [27]. Bacteria isolates were speciated with API $20 \mathrm{E}$ identification system (bioMerieux, France). For purposes of this study, only E. coli cultures were further analyzed [28].

\section{Antimicrobial susceptibility}

Escherichia coli cultures were subjected to Kirby-Bauer method of sensitivity testing per guidelines of the Clinical and Laboratory Standard Institute (CLSI) [29]. The following antibiotics were used: ampicillin $(10 \mu \mathrm{g})$, tetracycline $(30 \mu \mathrm{g})$, cotrimoxazole $(25 \mu \mathrm{g})$, nalidixic acid $(30 \mu \mathrm{g})$, nitrofurantoin $(300 \mu \mathrm{g})$, gentamicin $(10 \mu \mathrm{g})$ and cefuroxime $(30 \mu \mathrm{g})$. These antibiotics were selected because they are commonly used antibiotics for the treatment of bacterial infections in the general populace [21, 25]. Control strains included E. faecalis ATCC 29212, E. coli ATCC 25922, and Staphylococcus aureus ATCC 29213 (Additional file 1: S2 file).

\section{Molecular characterization}

Colonies of fresh bacterial culture were suspended in $200 \mathrm{ml}$ of sterile water. The suspension was heated at $98{ }^{\circ} \mathrm{C}$ for $10 \mathrm{~min}$ and centrifuged at $17,900 \mathrm{~g}$ for $5 \mathrm{~min}$.
The supernatant was recovered and used as templates for polymerase chain reactions (PCR). Gene amplification was done for $b l a_{\mathrm{TEM}}$; aminoglycoside resistant genes [Ia(aphA1), Ia(aphA2)], integrase genes I with II; and 18 virulent factors for ExPEC adhesions, toxins, iron capture systems, protectins, uropathogenic specific protein and aerobactin system (Additional file 1: S3 file) as previously reported [11, 30, 31]. Virulence factors (Vfs) for all the $E$. coli isolates were tested using primers by Johnson et al. $[5,6,9,11,30]$ and other authors [31-39] as these were reported to be sufficient to identify ExPECs. The virulent genes were amplified in 6 primer pools [1 (iron, sfa, iutA, hra), 2 (papA, KpsMTIII, ireA, ibeA), 3 (papG1, papGII, III, iha, omp T, KpsMTII), 4 (iuC, Cnf1, irp2), 5 (hlyD, usp, tra $\mathrm{T})$, and 6 (papC, sat, FyuA)] [11, 30, 31].

\section{Statistical analysis}

Data was analysed using GraphPad Prism software, version 6. Bacteriuria was defined as bacterial growth $>10^{5}$ colony forming units/mL per urine sample on CLED. Associations between socio-demographic characteristics and development of UTI, phenotypic resistance, and virulence factors were done using Chi square test. p-values $<0.05$ were considered significant.

\section{Results}

Overall, $42.8 \%(\mathrm{n}=171)$ of 400 participants had bacteriuria. Escherichia coli was the most predominant isolate (47.95\%), followed by Staphylococcus aureus (18.1\%), and Klebsiella pneumoniae (13.45\%) (Fig. 1).

Forty-four percent of pregnant women aged 13 to 19 years had UTI, with $E$. coli accounting for $33.3 \%$. Out of the 228 patients (aged 20-29 years), 96 (42.11\%) had

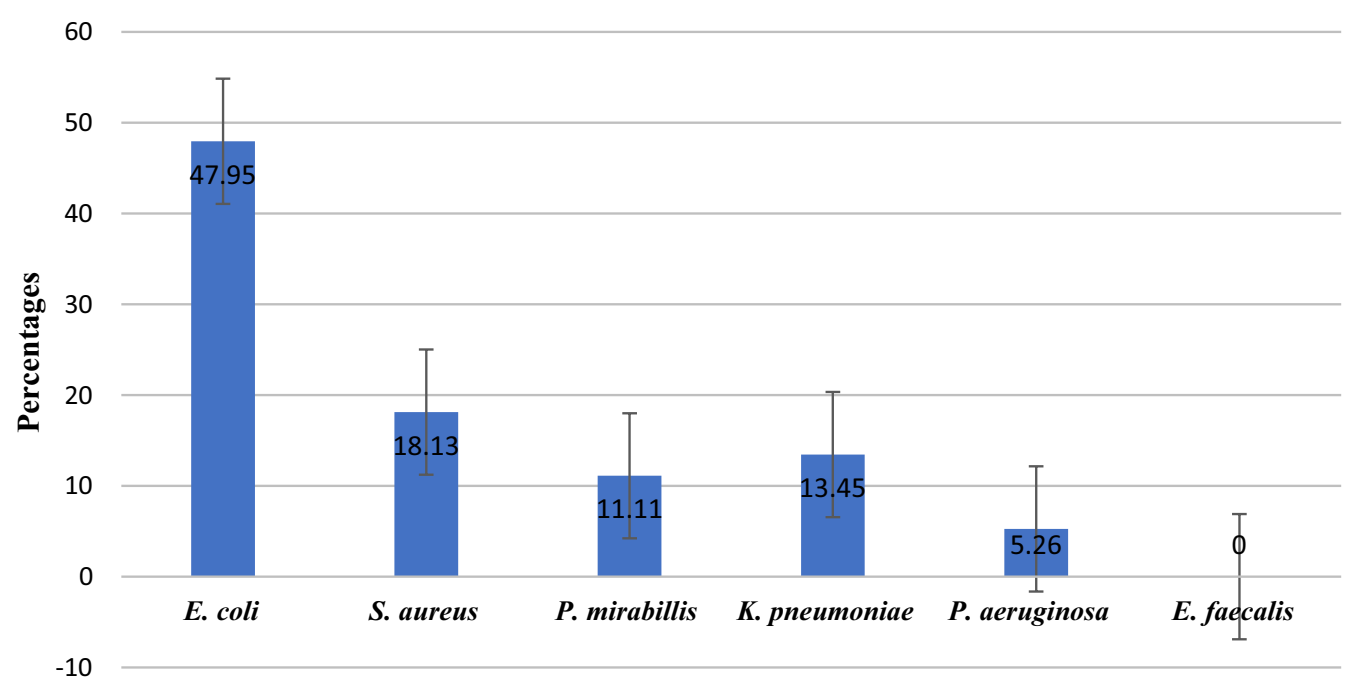

Fig. 1 Distribution of isolated bacteria 
UTI with $52.08 \%$ associated with E. coli (Additional file 1: S4 file). The rate of UTI in the 30-39 age groups was $42.18 \%$ and $E$. coli was associated with $50 \%$. The differences in the rate of UTI among the various age groups was statistically non-significant $(\mathrm{p}=0.706)$. Basic level education (62.7\%) and secondary education (25.5\%) were the common levels of education (Additional file 1: S4 file). One hundred and ten (43.8\%) of the women with basic education had UTI and $45.5 \%$ were infected with E. coli. Forty-five percent of the pregnant women with secondary education had UTI and E. coli was associated with $52.2 \%$ [23]. The differences in rate of UTI in relation to educational status was statistically non-significant $(p=0.262)$. Significant bacteria growth of $42.3 \%$ and $49.1 \%$ was found for women in 2nd and 3rd trimesters (Additional file 1: S4 file). Fifty-five percent of first trimester pregnant women with UTI were associated with E. coli. Chi square exact test revealed an association with gestational age and the development of UTI $(\mathrm{p}=0.002)$.

Escherichia coli isolates were highly resistant to ampicillin $(79.3 \%)$ and tetracycline (70.7\%) (Table 1). Whilst a resistance of $59.8 \%$ and $48.8 \%$ were found for cotrimoxazole and nalidixi acid, the least resistance was to cefuroxime (32.9\%) and nitrofurantoin (35.4\%).

In total, 49 (59.7\%) ampicillin resistant isolates contained $B l a_{\mathrm{TEM}}$ (Table 2). Pregnant women in the 2nd (24 isolates) and 3rd (18 isolates) trimesters had E. coli isolates with more $B l a_{\text {TEM }}$ gene compared to women in their 1 st trimesters (5 isolates). The aminoglycoside genes $\operatorname{aph}(3)-I a(\operatorname{aphA} 2)$ for gentamicin resistance was in 6 isolates from pregnant women in their 2nd and 3rd trimesters (Table 2). All the E. coli isolates were screened for the presence of intI and intII, however only 10 of isolates were positive for intI, whilst two $E$. coli isolates contained int II, 58 of the isolates did not possess either int $\mathrm{I}$ or int II.

The distribution of the $82 \mathrm{E}$. coli isolates in relation to virulence genes from the various groups of pregnant women revealed $75.6 \%$ (62 isolates) E. coli contained two or more virulence genes (VFs) (Table 2). The virulence score used to classify the ExPEC isolates was calculated using the total number of VFs genes. Isolates were classified as ExPEC if they were positive for two or more of the tested virulence genes [5]. The iutA (aerobactin acquisition), papC and iha (adhesins), fyuA and irp2 (iron capture systems), tra $\mathrm{T}$ (protectins) were the common detected genes, whereas usp (uropathogenic-specific proteins) and some of the adhesin genes ( $h r a, i b e A$, and pap $\mathrm{G} 1$ ) were the least.

VFs was widespread in pregnant women in the 2nd (30 isolates) and 3rd (25 isolates) trimesters than 1st trimester (12 isolates) (Table 2). In this study, all the E. coli isolates in women in their 1st trimester were ExPEC. Whilst 19 pregnant women in their 2nd trimesters (20-29 years) were positive for ExPEC, 13 women in the 3rd trimester (20-29 years) were positive. In addition, in the age group 40-49 years, only 2 women in the 3rd trimester were ExPEC positive, whilst one woman in the 2nd trimester was positive (Table 2).

\section{Discussion}

There are few studies on the antimicrobial susceptibility and/or virulence of $E$. coli isolates colonizing the genital tract of pregnant women [39-41]. However, no studies have been carried out to compare virulence factors and antimicrobial resistance in E. coli from pregnant in Ghana. This study revealed the $42.75 \%$ of the pregnant women with UTI was slightly lower than the $56.5 \%$ previously reported in Ghana by Boye et al. [26]. Although findings are similar to $47.5 \%$ from Nigeria [42], it is lower than the $85 \%$ reported by Turay et al. [43]. However, the $42.75 \%$ in this study is higher than reports from Thailand (5.1\%) and Ethiopia (18.8\%) [44, 45]. The difference in prevalences may be attributed to varied genital hygiene and socioeconomic conditions [46]. E. coli accounted for $47.95 \%$ of the UTI cases in the pregnant women. This is in conformity with

Table 1 Antibiotic resistance pattern of $E$. coli isolate

\begin{tabular}{|c|c|c|c|c|c|c|}
\hline \multirow[t]{2}{*}{ Antibiotic } & \multicolumn{5}{|l|}{ Hospitals (no.) } & \multirow[t]{2}{*}{ Total $(\mathrm{n}=82, \%)$} \\
\hline & $\begin{array}{l}\text { St. Joseph } \\
\text { hospital }(n=23 \text {, } \\
\%)\end{array}$ & $\begin{array}{l}\text { Volta regional } \\
\text { hospital }(n=11, \%)\end{array}$ & $\begin{array}{l}\text { Mary Theresa } \\
\text { hospital }(n=16, \%)\end{array}$ & $\begin{array}{l}\text { Ketu South Mun. } \\
\text { hospital }(n=18, \%)\end{array}$ & $\begin{array}{l}\text { St. Anthony } \\
\text { hospital }(n=14 \text {, } \\
\%)\end{array}$ & \\
\hline Ampicillin & 20 & 8 & 11 & 15 & 11 & 65 (79.3) \\
\hline Tetracycline & 18 & 8 & 10 & 12 & 10 & $58(70.7)$ \\
\hline Cotrimoxazole & 16 & 6 & 8 & 9 & 10 & 49 (59.8) \\
\hline Nalidixic acid & 8 & 6 & 8 & 11 & 7 & $40(48.8)$ \\
\hline Nitrofurantoin & 7 & 4 & 5 & 9 & 4 & $29(35.4)$ \\
\hline Gentamicin & 6 & 4 & 6 & 10 & 8 & $34(41.5)$ \\
\hline Cefuroxime & 6 & 3 & 3 & 12 & 3 & 27 (32.9) \\
\hline
\end{tabular}


Table 2 Distribution of VFs and resistance genes in $E$. coli isolates

\begin{tabular}{|c|c|c|c|c|c|c|}
\hline \multirow[t]{2}{*}{ Age } & \multicolumn{2}{|l|}{ 1st trimester } & \multicolumn{2}{|l|}{ 2nd trimester } & \multicolumn{2}{|l|}{ 3rd trimester } \\
\hline & Resist. genes & $\begin{array}{l}\text { Tested Vfs (no. } \\
\text { of positives) }\end{array}$ & Resist. genes & $\begin{array}{l}\text { Tested Vfs (no. } \\
\text { of positives) }\end{array}$ & Resist. genes & $\begin{array}{l}\text { Tested Vfs (no. } \\
\text { of positives) }\end{array}$ \\
\hline \multirow[t]{3}{*}{$13-19$} & $B l a_{\mathrm{TEM}}$ & iutA, irp, papC, FyuA(1) & $B / a_{\mathrm{TEM}}$, int 1 & irp, traT, FyuA(1) & $B l a_{\mathrm{TEM}}$, int $1, a p h A 2$ & iutA, irp, papC, FyuA(1) \\
\hline & & & $B l a_{\mathrm{TEM}}$ & iutA, iha, irp, traT(1) & $B l a_{\mathrm{TEM}}$ & $\begin{array}{l}\text { iutA, iron, iha, irp, traT, papC, } \\
\text { FyuA(1) }\end{array}$ \\
\hline & & & int1 & $\begin{array}{l}\text { iutA, papA, iha, irp, traT, } \\
\text { papC, FyuA(1) }\end{array}$ & $B / a_{\mathrm{TEM}}$ & $\begin{array}{l}\text { iron, ire, papA, iha, irp, papC, } \\
\text { FyuA(1) }\end{array}$ \\
\hline \multirow[t]{22}{*}{$20-29$} & - & irp, $\operatorname{traT}(1)$ & $B / a_{\mathrm{TEM}}$ & iha, irp, traT(1) & - & iha, irp(1) \\
\hline & $B / a_{\mathrm{TEM}}$ & iutA, iron, ire, papG1 (1) & $B l a_{\mathrm{TEM}}$, int 1 & $\operatorname{irp}(1)$ & $B / a_{\mathrm{TEM}}$ & $-(2)$ \\
\hline & int1 & iutA, papA, iha, irp, $\operatorname{traT}(1)$, & $B l a_{\mathrm{TEM}}$, int 1 & $\operatorname{traT}(1)$ & $B / a_{\mathrm{TEM}}$ & iutA, hra, iha, irp, FyuA(1) \\
\hline & $B l a_{\mathrm{TEM}}$, int 1 & $\begin{array}{l}\text { iutA, ompT, papG1, irp, } \\
\operatorname{traT(1)}\end{array}$ & - & iha, omp T(1) & $B / a_{\mathrm{TEM}}$ & iutA, papG1, irp, traT, FyuA(2) \\
\hline & int1 & $\begin{array}{l}\text { iutA, sfa, hra, iron, iha, } \\
\text { ompT, irp2, traT(1) }\end{array}$ & $B l a_{\mathrm{TEM}}$ & irp, traT, FyuA(1) & $B / a_{\mathrm{TEM}}$ & $\begin{array}{l}\text { iutA, ompT, irp, papC, } \\
\text { FyuA(1) }\end{array}$ \\
\hline & int2 & $\begin{array}{l}\text { iutA, sfa, iron, iha, kpsM- } \\
\quad \Pi 1(1)\end{array}$ & $B l a_{\mathrm{TEM}}$ & iutA, traT, FyuA(1) & $B l a_{\mathrm{TEM}}$, int 1 & iutA, irp, traT, papC, FyuA(1) \\
\hline & & irp, traT, papC, FyuA(1) & & & & \\
\hline & int2 & iutA, sfa, papA, iron, papA & $B l a_{\mathrm{TEM}}$ & iha, irp, $\operatorname{traT}(1)$ & $B / a_{\mathrm{TEM}}$ & iron, irp, traT, papC, FyuA(1) \\
\hline & & Iha, irp, papC, FyuA(1) & $B l a_{\mathrm{TEM}}$, int 1 & iutA, irp, iuC(1) & $B / a_{\mathrm{TEM}}, a p h A 2$ & iutA, ompT, irp, traT, FyuA(1) \\
\hline & & & - & iutA, ompT, irp, traT(1) & $B / a_{\mathrm{TEM}}$ & $\begin{array}{l}\text { iutA, ompT, irp, iuc, papC, } \\
\text { FyuA(1) }\end{array}$ \\
\hline & & & - & iutA, hra, ire, traT(1) & $B / a_{\mathrm{TEM}}$ & $\begin{array}{l}\text { iutA, iron, ompT, irp, papC, } \\
\text { FyuA(1) }\end{array}$ \\
\hline & & & $B l a_{\mathrm{TEM}}, a p h A 2$ & kpsMTIII, irp, papC, FyuA(1) & - & $\begin{array}{l}\text { iutA, papA, iron, irp, papC, } \\
\text { FyuA(1) }\end{array}$ \\
\hline & & & $B l a_{\mathrm{TEM}}$ & iutA, iha, irp, FyuA(1) & - & $\begin{array}{l}\text { iutA, sfa, papA, iha, irp, papC, } \\
\text { FyuA(1) }\end{array}$ \\
\hline & & & $B \mid a_{\mathrm{TEM}}$ & ompT, irp, traT, usp(1) & - & $\begin{array}{l}\text { sfa, hra, iha, kpsMTIl, irp, traT, } \\
\text { FyuA(1) }\end{array}$ \\
\hline & & & $B l a_{\mathrm{TEM}}$ & iha, irp, traT, papC, FyuA(1) & & \\
\hline & & & - & $\begin{array}{l}\text { iutA, irp, traT, papC, } \\
\text { FyuA(1) }\end{array}$ & & \\
\hline & & & $B l a_{\mathrm{TEM}}$ & $\begin{array}{l}\text { iha, papG1, irp, papC, } \\
\text { FyuA(1) }\end{array}$ & & \\
\hline & & & $B l a_{\mathrm{TEM}}, a p h A 2$ & $\begin{array}{l}\text { iutA, iron, ire, iha, ompT, } \\
\text { traT, } p a p C, \text { FyuA(1) }\end{array}$ & & \\
\hline & & & $B / a_{\mathrm{TEM}}, a p h A 2$ & $\begin{array}{l}\text { iutA, iron, ire, iha, ompT, } \\
\text { traT, papC, FyuA(1) }\end{array}$ & & \\
\hline & & & $B l a_{\mathrm{TEM}}$ & $\begin{array}{l}\text { sfa, iron, ire, iha, irp, traT, } \\
\text { hlyD, papC, FyuA(1) }\end{array}$ & & \\
\hline & & & 0 & $\begin{array}{l}\text { iutA, sfa, iron, kpsMTIII, } \\
\text { iha, ompT, traT, papC, } \\
\text { FyuA(1) }\end{array}$ & & \\
\hline & & & $B l a_{\mathrm{TEM}}$ & $\begin{array}{l}\text { sfa, iron, ire, papA, iha, irp, } \\
\text { traT, hlyD, papC, FyuA(1) }\end{array}$ & & \\
\hline \multirow[t]{6}{*}{$30-39$} & $B l a_{\mathrm{TEM}}$, int 1 & irp, traT, FyuA(1) & $B l a_{\mathrm{TEM}}$ & $\operatorname{irp}(1)$ & 0 & iutA, irp, papC, FyuA(1) \\
\hline & $B / a_{\text {TEM }}$ & $\begin{array}{l}\text { iutA, ompT, irp, papC, } \\
\text { FyuA(1) }\end{array}$ & - & iutA, iha(1) & 0 & iha, irp, traT, usp, FyuA(1) \\
\hline & & & $B l a_{\mathrm{TEM}}$ & iutA, iron, iha(1) & $B a_{\mathrm{TEM}}$, int 1 & $\begin{array}{l}\text { iutA, papG1, irp, papC, } \\
\text { FyuA(1) }\end{array}$ \\
\hline & & & $B l a_{\mathrm{TEM}}$ & iutA, iha, irp, traT(2) & - & papA, irp, traT, papC, FyuA(1) \\
\hline & & & - & iutA, ompT, irp, FyuA(1) & $B l a_{\mathrm{TEM}}$ & $\begin{array}{l}\text { iutA, ibe, ompT, kpsMTII, traT, } \\
\text { FyuA(1) }\end{array}$ \\
\hline & & & $B / a_{\mathrm{TEM}}$ & iutA, irp, iuC, papC, FyuA(1) & $B / a_{\mathrm{TEM}}$, int 1 & $\begin{array}{l}\text { iutA, ompT, irp, traT, papC, } \\
\text { FyuA(1) }\end{array}$ \\
\hline
\end{tabular}


Table 2 (continued)

\begin{tabular}{|c|c|c|c|c|c|c|}
\hline \multirow[t]{2}{*}{ Age } & \multicolumn{2}{|l|}{$1 \mathrm{st}$ trimester } & \multicolumn{2}{|l|}{ 2nd trimester } & \multicolumn{2}{|l|}{ 3rd trimester } \\
\hline & Resist. genes & $\begin{array}{l}\text { Tested Vfs (no. } \\
\text { of positives) }\end{array}$ & Resist. genes & $\begin{array}{l}\text { Tested Vfs (no. } \\
\text { of positives) }\end{array}$ & Resist. genes & $\begin{array}{l}\text { Tested Vfs (no. } \\
\text { of positives) }\end{array}$ \\
\hline & & & $B l a_{\text {TEM }}$ & iutA, ire, ompT, irp, $\operatorname{traT}(1)$ & $B l a_{\mathrm{TEM}}, a p h A 2$ & $\begin{array}{l}\text { iutA, papA, ompT, irp, traT, } \\
\text { FyuA(1) }\end{array}$ \\
\hline & & & & & - & $\begin{array}{l}\text { iutA, papA, iha, irp, traT, } \\
\text { papC, FyuA(1) }\end{array}$ \\
\hline \multirow[t]{2}{*}{$40-49$} & - & - & - & $\operatorname{irp}, F y u A(1)$ & $B l a_{\text {TEM }}$ & $\begin{array}{l}\text { iutA, papA, irp, traT, papC, } \\
\text { FyuA(1) }\end{array}$ \\
\hline & & & & & $B l a_{\text {TEM }}$ & $\begin{array}{l}\text { ire, papA, iha, irp, traT, papC, } \\
\text { FyuA(1) }\end{array}$ \\
\hline $\begin{array}{c}\text { Total no. } \\
\text { genes/ } \\
\text { ExPECs }\end{array}$ & 9 & 12 & 25 & 30 & 18 & 25 \\
\hline
\end{tabular}

previous studies from Sudan, Bangladesh, and Nigeria [47-49]. The high incidence of $E$. coli associated with UTI among the pregnant women may be attributed to poor genital hygiene practices [50].

Multiparity, gestational age, history of UTI and anatomic urinary tract abnormalities are reported to affect the frequency of bacteriuria during pregnancy $[51,52]$. Pregnant women in their 3rd trimester recorded the highest incidence of UTI (49.13\%), followed by those in 2nd trimester (43.25\%). Finding are conformity with studies from Bangladesh, Iran Ethiopia, Yemen, and India [48, 53-55]. Although Chi square exact test revealed a statistical association of UTI and gestational age $(p=0.002)$, it is in contrast to studies from Nigeria $[20,43]$. Furthermore, the prevalence of UTI was found to increase with parity in this study. This findings however are in contrast to Emiru et al. [51] and Nandy et al. [56] studies.

Escherichia coli isolates were highly resistant to ampicillin, and tetracycline. Findings are similar to earlier studies in Ghana [21, 57, 58]. The high levels of resistance can be attributed to abuse of these drugs over the years because the drugs are relatively cheap and easily accessible $[21,58]$. A considerable number of the bacteria harboured the iutA (aerobactin acquisition), papC and iha (adhesins), fyuA and irp2 (iron capture systems), and tra $\mathrm{T}$ genes $[59,60]$. In contrast to Sáez-López et al. [41] study with pregnant women in Barcelona, the ExPEC isolates in this study showed high antimicrobial resistance as previously reported in some African countries [61, 62]. In addition, the ampicillin resistant ExPEC isolates containing $B l a_{\text {TEM }}$ gene showed a greater number of VFs in comparison with tetracycline or gentamicin resistant isolates. Our findings however, are dissimilar to Ramos et al. [63] study with pregnant women in Sweden, Uganda, and Vietnam [63]. The differences in the studies may be due to varying geographical area, host physiological changes or susceptibility to $E$. coli isolates with pathogenic islands containing VFs [64].

\section{Conclusion}

In conclusion, our results demonstrates that antibiotic resistant ExPEC associated with UTI in some Ghanaian pregnant women have virulence properties which enables them to adhere, invade and utilize the iron acquisition systems. Information from this study is useful to develop appropriate interventions to avoid maternal and/neonatal infections with asymptomatic pathogens during obstetric care.

\section{Limitations}

The study focused on asymptomatic infection rather than symptomatic infection and included only few hospitals in Ghana, thereby not allowing extrapolation of our results to other regions.

\section{Additional file}

Additional file 1: S1 File. Questionnaire for demographic data collection. S2 File. Guidelines for interpreting antimicrobial susceptibility results. S3 File. Primers used for PCR. S4 File. Socio-demographic characteristics and distribution of UTI.

\section{Abbreviations}

VFs: virulence factors; UTI: urinary tract infections; E. coli: Escherichia coli; ExPEC: extraintestinal pathogenic E. coli; PCR: polymerase chain reactions; CLED: cysteine lactose electrolyte deficient; CLSI: Clinical and Laboratory Standard Institute. 


\section{Authors' contributions}

FOA conceived and designed the experiments and draft the manuscript, WBT performed the experiments, MNQ assisted with experimental analysis, NON analysed and interpreted the data, DNA assisted in drafting the manuscript and substantial contributions for the conception of the study design and co-ordination. All authors were involved in revising the manuscript. All authors read and approved the final manuscript.

\section{Acknowledgements}

The authors would like to express their gratitude to all the staff of St Joseph, Volta regional, Mary-Theresa, Ketu South and St Anthony Hospitals and all the pregnant women for their cooperation and support during the various aspects of the study. Special thanks to Dr. James R. Johnson, Adam L. Stell and Brian Johnston of the University of Minnesota, Department of Medicine and Infectious Diseases for providing the positive controls for the virulence factors and resistant genes.

\section{Competing interests}

The authors declare that they have no competing interests.

\section{Availability of data and materials}

The datasets used and/or analyzed during the current study are available from the corresponding author on reasonable request.

\section{Consent to publish}

Not applicable.

\section{Ethics approval and consent to participate}

The study was approved by the Ethics Committee of the School of Biomedical and Allied Health Sciences, College of Health Sciences, University of Ghana, Legon (Ethics Identification Number: SAHS/10507884/AA/MLS/2015-2016). Participation was voluntary and written consent was taken in accordance with the ethical committee's guidelines. Pregnant minors (age > 16) attending the selected hospitals were only included in the study after a signed written informed consent was obtained from only the parents. Permission was also sought from the Volta Region Ghana Health Service before the samples were taken.

\section{Funding}

This research received no specific grant from any funding agency in the public, commercial, or not-for-profit sectors.

\section{Publisher's Note}

Springer Nature remains neutral with regard to jurisdictional claims in published maps and institutional affiliations.

Received: 13 October 2018 Accepted: 5 December 2018 Published online: 17 December 2018

\section{References}

1. Gilbert NM, O'Brien VP, Scott H, Macones G, Lewis WG, Lewis AL. Urinary tract infection as a preventable cause of pregnancy complications: opportunities, challenges, and a global call to action. Global Adv Health Med. 2013;2(5):59-69.

2. Ayub M, Amir JS, Firdous K, et al. E. coli the most prevalent causative agent urinary tract infection in pregnancy: comparative analysis of susceptibility and resistance pattern of antimicrobials. Arch Clin Microbiol. 2016;7:4. https://doi.org/10.4172/1989-8436.100054.

3. Sabir S, Anjum AA, ljaz T, Ali MA, Khan MR, Nawaz M. Isolation and antibiotic susceptibility of $E$. coli from urinary tract infections in a tertiary care hospital, Pakistan. J Med Sci. 2014;30(2):389-92.

4. Farshad S, Anvarinejad M, Tavana AM, Ranjbar R, Japoni A, Zadegan RM, Alborzi A. 'Molecular epidemiology of Escherichia coli strains isolated from children with community acquired urinary tract infections. Afr J Microbiol Res. 2011;5(26):4476-83.
5. Russo TA, Johnson JR. Extraintestinal pathogenic Escherichia coli. In: Alan RS, editor. Vaccines for biodefense and emerging and neglected diseases. London: Academic Press; 2009. p. 939-61.

6. Johnson JR, Stell AL. Extended virulence genotypes of Escherichia coli strains from patients with urosepsis in relation to phylogeny and host compromise. J Infect Dis. 2000;181(1):261-72.

7. Belanger L, Garenaux A, Harel J, Boulianne M, Nadeau E, Dozois CM. Escherichia colifrom animal reservoirs as a potential source of human extraintestinal pathogenic E. coli. FEMS Immunol Med Microbiol. 2011;62(1):1-10.

8. Kohler CD, Dobrindt U.' What defines extraintestinal pathogenic Escherichia coli? Int J Med Microbiol. 2011;301(8):642-7.

9. Johnson JR, Russo TA. Extraintestinal pathogenic Escherichia coli: the other bad E. coli. J Lab Clin Med. 2002;139(3):155-62.

10. Graziani C, Luzzi I, Corro M, Tomei F, Parisi G, Giufre M, Morabito S, Caprioli A, Cerquetti M. Phylogenetic background and virulence genotype of ciprofloxacin-susceptible and ciprofloxacin-resistant Escherichia coli strains of human and avian origin. J Infect Dis. 2009;199(8):1209-17.

11. Johnson TJ, Wannemuehler Y, Johnson SJ, Stell AL, Doetkott C, Johnson JR, Kim KS, Spanjaard L, Nolan LK. Comparison of extraintestinal pathogenic Escherichia coli strains from human and avian sources reveals a mixed subset representing potential zoonotic pathogens. Appl Environ Microbiol. 2008;74(22):7043-50.

12. Ramos NL, Saayman ML, Chapman TA, Tucker JR, Smith HV, Faoagali J, et al. Genetic relatedness and virulence gene profiles of Escherichia coli strains isolated form septiaemic and uroseptic patients. Eur J Clin Microbiol Infect Dis. 2010;29:15-23.

13. Matuszkiewicz-Rowińska J, Małyszko J, Wieliczko M. Urinary tract infections in pregnancy: old and new unresolved diagnostic and therapeutic problems. Arch Med Sci. 2015;11(1):67-77.

14. McNally A, Alhashash F, Collins M, Alqasim A, Paszckiewicz K, Weston V, Diggle M. Genomic analysis of extra-intestinal pathogenic Escherichia coli urosepsis. Clin Microbiol Infect. 2013;19:E328-34.

15. Salipante SJ, Roach DJ, Kitzman Snyder M W, Stackhouse B, Butler-Wu SM, Lee C, Cookson BT, Shendure J. Large-scale genomic sequencing of extraintestinal pathogenic Escherichia coli strains. Genome Res. 2014;25:119-28.

16. World Health Organization Media Release. WHO's first global report on antibiotic resistance reveals serious, worldwide threat to public health. http://www.who.int/mediacentre/news/releases/2014/amr-report/en. Accessed 25 June 2014

17. Mukherjee M, Koley S, Mukherjee S, Basu S, Ghosh B, Chakraborty S. Phylogenetic background of E. coli isolated from asymptomatic pregnant women from Kolkata. J Infect Develop Ctries. 2015;9(7):720-4.

18. Al-Mayahie SM. Phenotypic and genotypic comparison of ESBL production by vaginal Escherichia coli isolates from pregnant and non-pregnant women. Ann Clin Microbiol Antimicrob. 2013;25(12):7. https://doi. org/10.1186/1476-0711-12-7.

19. Alemu A, Moges F, Shiferaw Y, Tafess K, Kassu A, Anagaw B, Agegn A Bacterial profile and drug susceptibility pattern of urinary tract infection in pregnant women at University of Gondar Teaching Hospital, Northwest Ethiopia. BMC Res Notes. 2012;5:197.

20. Onoh RC, Umeora OUJ, Egwuatu VE, Ezeonu PO, Onoh TJP. Antibiotic sensitivity pattern of Uropathogens from pregnant women with urinary tract infection in Abakaliki, Nigeria. Infect Drug Resist. 2013;6:225-33.

21. Newman MJ, Frimpong E, Donkor ES, Opintan JA, Asamoah-Adu A. Resistance to antimicrobial drugs in Ghana. Infect Drug Resist. 2011:4:215-20.

22. Donkor ES, Akumwena A, Amoo KP, Owolabi MO, Aspelund T, Gudnason $\checkmark$. Post-stroke bacteriuria among stroke patients attending a physiotherapy clinic in Ghana: a cross-sectional study. Ther Clin Risk Manag. 2016;12:457-62.

23. Donkor ES, Osei JA, Anim-Baidoo I, Darkwah S. Risk of asymptomatic bacteriuria among people with sickle cell disease in Accra, Ghana. Diseases. 2007:5:4.

24. Ghana Statistical Service. 2010 population and housing census. Summary report of final results. Accra: GSS; 2012.

25. Opintan Japheth A, Newman Mercy J, Arhin Reuben E, Donkor Eric S, Gyansa-Lutterodt Martha, Mills-Pappoe William. Laboratory-based nationwide surveillance of antimicrobial resistance in Ghana. Infect Drug Resist. 2015;8:379-89. 
26. Boye A, Siakwa PM, Boampong JN, Koffuor GA, Ephraim RKD, Amoateng P, Obodai G, Penu D. Asymptomatic urinary tract infections in pregnant women attending antenatal clinic in Cape Coast, Ghana. J Med Res. 2012;1 (6):74-83

27. Acharya T. 2015. API 20E Test System: Introduction, Procedure Results and Interpretations. http://microbeonline.com/api-20e-test-system-introducti on-procedure-results-interpretations/. Accessed 10 Aug 2017.

28. Standards Unit, Microbiology Services, UK Standards for Microbiology Investigations Investigation of Urine, PHE, 2014 B 41, 7(2). http://forte -medical.co.uk/wp-content/uploads/2015/07/PHE-UK-standards-formicrobiologyinvestigation-of-urine.pdf.

29. CLSI. Performance stardards for antimicrobial disk diffusion tests. Approved Standard CLSI documents MO2-12. 12th ed. Wayne: Clinical and Laboratory Standards Institutes; 2015.

30. Johnson JR, et al. Experimental mouse lethality of Escherichia coli isolates, in relation to accessory traits, phylogenetic group, and ecological source. J Infect Dis. 2006;194:1141-50.

31. Obeng AS, Rickard H, Ndi O, Sexton M, Barton MD. Antibiotic resistance and phylogenetic typing in commensal Escherichia coli from intensively farmed and free range poultry. Vet Microbiol. 2012;154:305-15.

32. Maynard C, Bekal S, Sanschagrin F, Levesque RC, Brousseau R, Masson L, Lariviere S, Harel J. Heterogeneity among virulence and antimicrobial resistance gene profiles of extraintestinal Escherichia coli isolates of animal and human origin. J Clin Microbiol. 2004;42(12):5444-52.

33. Saenz Y, Brinas L, Dominguez E, Ruiz J, Zarazaga M, Vila J, Torres C. Mechanisms of resistance in multiple-antibiotic-resistant Escherichia coli strains of human, animal, and food origins. Antimicrob Agents Chemother. 2004;48(10):3996-4001.

34. Johnson JR, Russo TA, Tarr PI, Carlino U, Bilge SS, Vary JC Jr, Stell AL. Molecular epidemiological and phylogenetic associations of two novel putative virulence genes, iha and iroN(E. coli), among Escherichia coli isolates from patients with urosepsis. Infect Immun. 2000;68(5):3040-30407.

35. Johnson JR, Gajewski A, Lesse AJ, Russo TA. Extraintestinal pathogenic Escherichia coli as a cause of invasive non urinary infections. J Clin Microbiol. 2003:41(12):5798-800.

36. Skyberg JA, Horne SM, Giddings CW, Wooley RE, Gibbs PS, Nolan LK. Characterizing avian Escherichia coli isolates with multiplex polymerase chain reaction. Avian Dis. 2003:47:1441-7.

37. Bauer RJ, Zhang L, Foxman B, Siitonen A, Jantunen ME, Saxen H, Marrs CF. Molecular epidemiology of 3 putative virulence genes for Escherichia coli urinary tract infection- usp, iha, and iroNE. J Infect Dis. 2002:185(10):1521-4.

38. Paixão AC, Ferreira AC, Fontes M, Themudo P, Albuquerque T, Soares MC, Fevereiro M, Martins L, Corrêa de Sá MI. Detection of virulence-associated genes in pathogenic and commensal avian Escherichia coli isolates. Poult Sci. 2016;95(7):1646-52.

39. Guiral E, Bosch J, Vila J, Soto SM. Prevalence of Escherichia coli among samples collected from the genital tract in pregnant and non pregnant women: relationship with virulence. FEMS Microbiol Lett. 2011;314:170-3.

40. Watt S, Lanotte P, Mereghetti L, Moulin-schouleur M, Picard B, Quentin R. Escherichia coli strains from pregnant women and neonates: intraspecies genetic distribution and prevalence of virulence factors. J Clin Microbiol. 2003:41:1929-35.

41. Sáez-López E, Guiral E, Fernández-Orth D, Villanueva S, Goncé A, López $M$, et al. Vaginal versus obstetric infection Escherichia coli isolates among pregnant women: antimicrobial resistance and genetic virulence profile. PLoS ONE. 2016;11(1):e0146531. https://doi.org/10.1371/journ al.pone.0146531.

42. Okonko IO, Donbraye-Emmanuel OB, ljandipe LA, Ogun AA, Adedeji AO, Udeze AO. Antibiotics sensitivity and resistance patterns of uropathogens to nitrofurantoin and nalidixic acid in pregnant women with urinary tract infections in ibadan, Nigeria. Middle-East J Sci Res. 2009:4(2):105-9.

43. Turay AA, Eke SO, Oleghe PO, Ozekhome MC. The prevalence of urinary tract infections among pregnant women attending antenatal clinic at Ujoelen primary health care centre, Ekpoma, Edo state, Nigeria. IJBAIR. 2014;3(1):86-94

44. Lumbiganon P, Villar J, Laopaiboon M, Widmer M, Thinkhamrop J, Carroli G, Duc Vy N, Mignini L, Festin M, Prasertcharoensuk W, Limpongsanurak S, Liabsuetrakul T, Sirivatanapa P. One-day compared with 7-day nitrofurantoin for asymptomatic bacteriuria in pregnancy: a randomized controlled trial. Obstet Gynecol. 2009;113(2 Pt 1):339-45.
45. Tadesse E, Teshome M, Merid Y, Kibret B, Shimelis T. Asymptomatic urinary tract infection among pregnant women attending the antenatal clinic of Hawassa Referral Hospital, Southern Ethiopia. BMC Res Notes. 2014;7:155.

46. Tazebew D, Getenet B, Selabat M, Wondewosen T. Urinary bacterial profile and antibiotic susceptibility pattern among pregnant women in North West Ethiopia. Ethiopian J Health Sci. 2012;22(2):121-8.

47. Hamdan ZH, Abdel Haliem M, Ziad Salah K, Ali Ishag Adam. Epidemiology of urinary tract infections and antibiotics sensitivity among pregnant women at Khartoum North Hospital. Ann Clin Microbiol Antimicrob. 2011;10:2.

48. Kawser $\mathrm{P}$, Afroza $\mathrm{M}$, Arzumath $\mathrm{AB}$, Monowara B. Prevalence of urinary tract infection during pregnancy. J Dhaka Natl Med Coll Hospital. 2011;17(02):8-12.

49. Akobi OA, Inyinbor HE, Akobi EC, Emumwen EG, Ogedengbe SO, Uzoigwe EO, Agbayani RO, Emumwen EF, Okorie IE. Incidence of urinary tract infection among pregnant women attending antenatal clinic at Federal Medical Centre, Bida, Niger-State, North Central Nigeria. Am J Infect Dis Microbiol. 2014;2(2):34-8.

50. Sheerin NS. Urinary tract infection (Obstruction and Infection). Medicine. 2015;43(8):435-9.

51. Emiru T, Beyene G, Tsegaye W, Melaku S. Associated risk factors of urinary tract infection among pregnant women at Felege Hiwot Referral Hospital, Bahir Dar, North West Ethiopia. BMC Res Notes. 2013;6:292.

52. Enayat K, Fariba F, Bahram N. Asymptomatic bacteriuria among pregnant women referred to outpatient clinics in Sanandaj, Iran. Int Brazilian J Urol. 2008;34:699-707.

53. Ferede G, Yismaw G, Wondimeneh Y, Sisay Z. The prevalence and antimicrobial susceptibility pattern of bacterial uropathogens isolated from pregnant women. Eur J Exp Biol. 2012;2(5):1497-502.

54. Al-Haddad AM. Urinary tract infection among pregnant women in AlMukalla district, Yemen. East Mediterranean Health J. 2005;11(3):505-10.

55. Sibi G, Kumari P, Neema K. Antibiotic sensitivity pattern from pregnant women with urinary tract infection in Bangalore, India. Asian Pac J Trop Med. 2014;7(Suppl 1):S116-20.

56. Nandy P, Thakur AR, Ray CS. Characterization of bacterial strains isolated through microbial profiling of urine samples. OnLine J Biol Sci. 2007;7:44-51.

57. Feglo P. Antimicrobial sensitivity patterns of urine isolates at the KomfoAnokye Teaching Hospital, (KATH) Kumasi, 2000-2005. Ghana J Allied Health Sci. 2007;1(2):43-9.

58. Newman MJ, Frimpong E, Asamoah-Adu A, Donkor ES. Resistance to antimicrobial drugs in Ghana. The Ghanaian-Dutch Collaboration for Health Research and Development. 2006; pp. 1-19. https://www.resea rchgate.net/profile/Japheth_Opintan/publication/221760926_Resistance _to_antimicrobial_drugs_in_Ghana/links/09e41502445a36821a000000/ Resistance-to-antimicrobial-drugs-in-Ghana.pdf.

59. Johnson JR, Delavari P, O'Bryan TT, Smith KE, Tatini S. Contamination of retail foods, particularly Turkey, from community markets (Minnesota, 1999-2000) with antimicrobial-resistant and extraintestinal pathogenic Escherichia coli. Foodborne Pathogens Dis. 2005;2(1):38-49.

60. Johnson JR, McCabe JS, White DG, Johnston B, Kuskowski MA, McDermott P. Molecular analysis of Escherichia coli from retail meats (2002-2004) from the United States national antimicrobial resistance monitoring system. Clin Infect Dis. 2009;49(2):195-201.

61. Motayo BO, Ogiogwa IJ, Okerentugba PO, Innocent-Adiele HC, Nwanze JC, Onoh CC, et al. Antimicrobial resistance profile of extra-intestinal Escherichia coli infections in a South Western Nigerian City. J Microbiol Res. 2012;2:141-4.

62. Mshana SE, Matee M, Rweyemamu M. Antimicrobial resistance in human and animal pathogens in Zambia, Democratic Republic of Congo, Mozambique and Tanzania: an urgent need of a sustainable surveillance system. Ann Clin Microbiol Antimicrob. 2013;12:28.

63. Ramos NL, Sekikubo M, Dzung DTN, Kosnopfel C, Kironde F, Mirembe F, Braunera A. Uropathogenic Escherichia coli isolates from pregnant women in different countries. J Clin Microbiol. 2012;50(11):3569-74.

64. Amiri FN, Rooshan MH, Ahmady MH. Hygiene practices and sexual activity associated with urinary tract infection in pregnant women. East Mediterranean Health. 2009;15:104-10. 